المنحني الخصائصي الأنسب لكينماتيكية مر احل أداء سباق · . r متر عدو

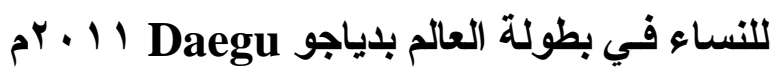
' ب الد / زكريا حسن حسن شحاتة

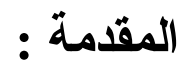

تعرض منافسات أداء العداءات فى سباقات العدو فى المضمار معدلات دالة احصائيا للنطوير فى السنو ات الأخيرة ، و أسباب هذا النطور كثيرة قد

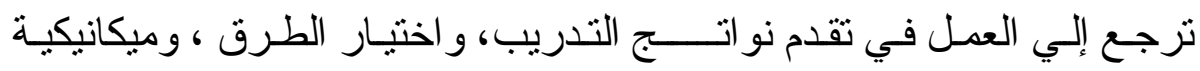

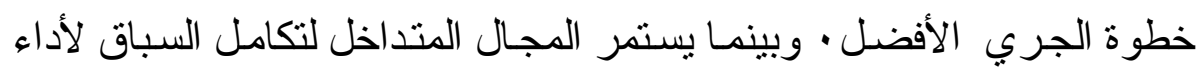
أسر ع وقت ( كما يحدث من دورة ألعاب اوليمبية لأخرى أو من بطولة أوربيـة الأبية

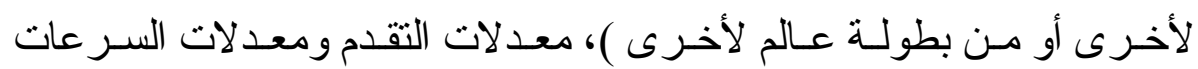

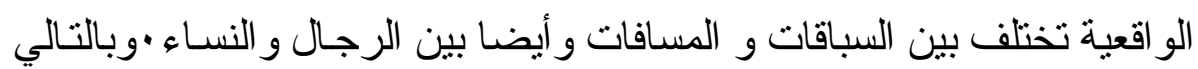

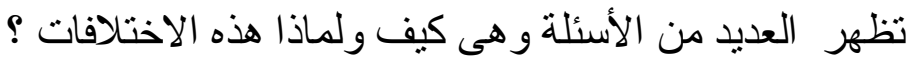

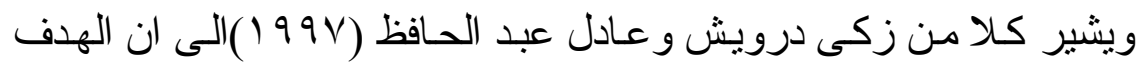

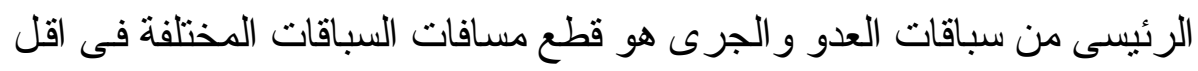

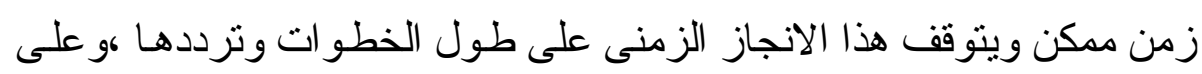

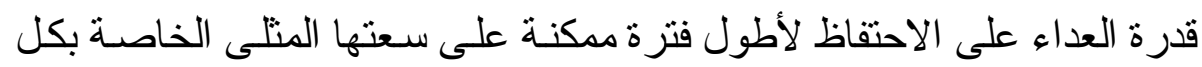

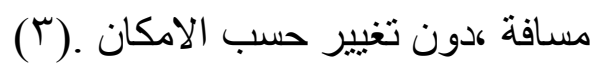

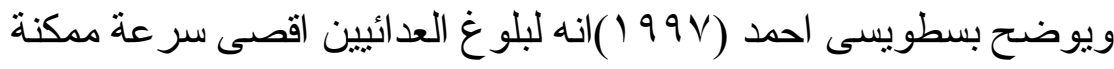
يجب خلق الانسجام الجيد و العلاقة الأكيدة بين طول الخطوة وترددها حيث انهم

'د / زكريـا حسن حسن شـحاتة: مدرس بقسم علوم الحركـة الرياضية، كلية التزبية الرياضية بدمياط، جامعة دمياط. 
يعطيان النتيجة النهائية لسرعة العداء أو العداءة بالاضـافة الى التأثثر الايجابى

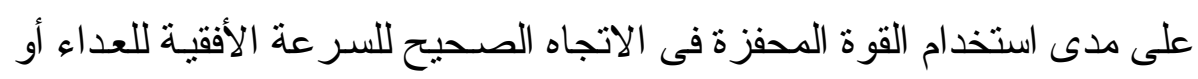

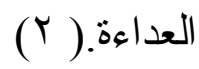

ويشير أوليغ كولودى و آخرون (910 (1) إلي أن المهمة الأساسية للعداء

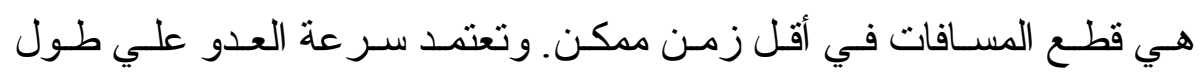

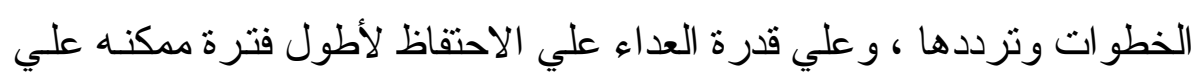

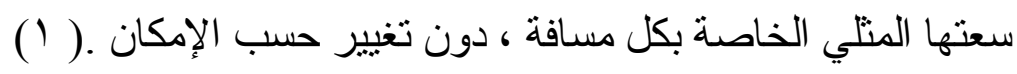

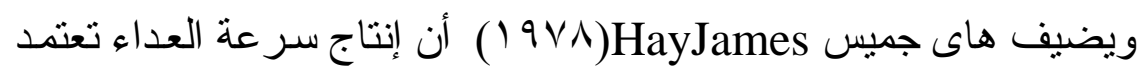

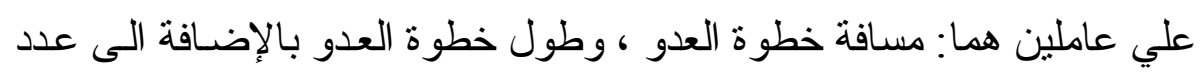

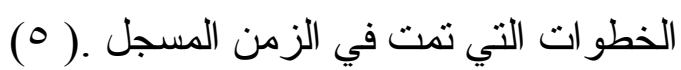

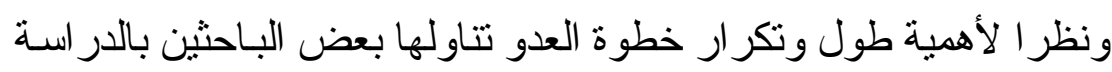

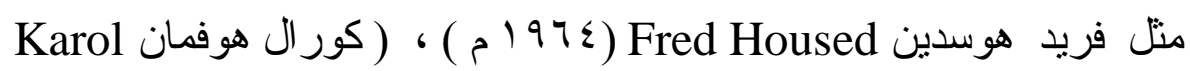
الر Hoffman

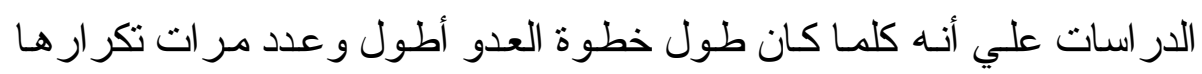

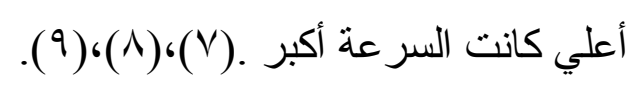

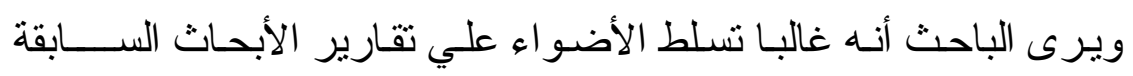

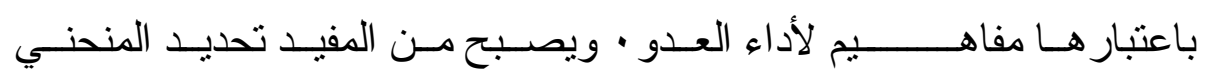

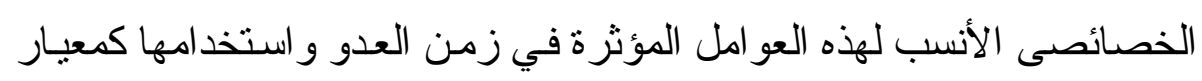
لتتخيص مخرجات أداء العدو. لذا هدفت هذه الدراسـة إلـي التعرف علـي الدقادير الكميـة الكينماتيكيـة

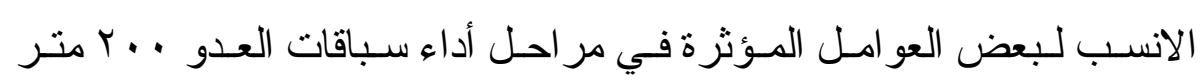

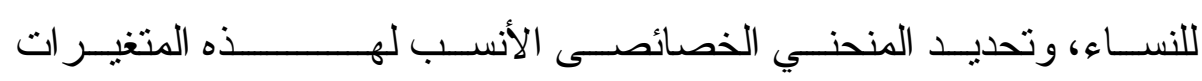
الكينماتيكية. 


\section{هدف البحث:}

هدفت هذه الار اسة إلي التعرف علي المنحنى الخصائصى الأنسب

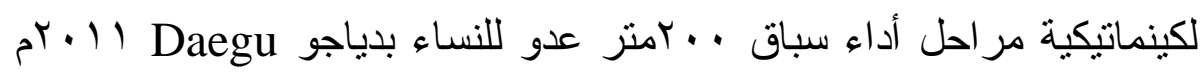
من خلال التعرف على ما يلي: !. المقادير الكمية لكل من زمن المسافة 00 متر الأولي، متوسط سـرعة

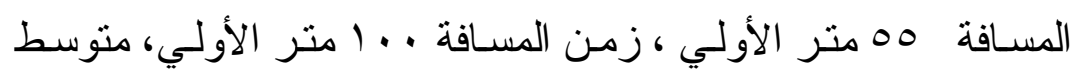

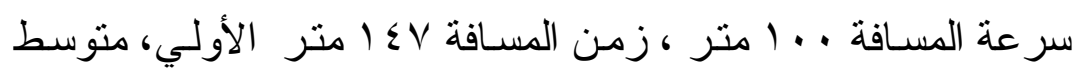

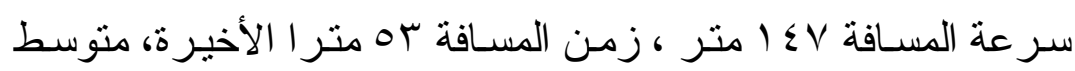

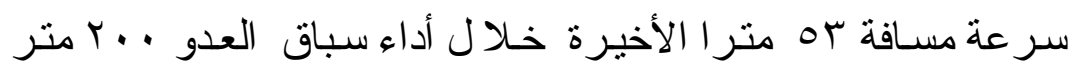
للنساء ץ. المنحني الخصائصي الأنسب لكل من زمن المسافة 00 متر الأولي،

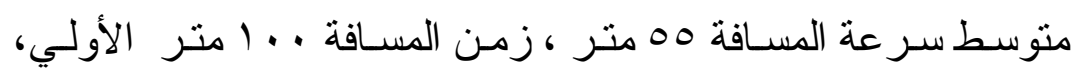

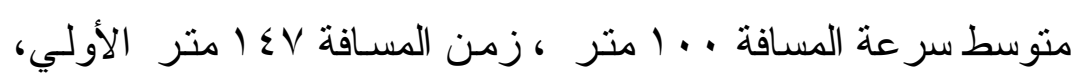

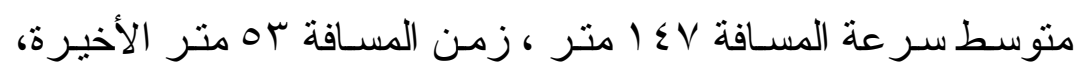

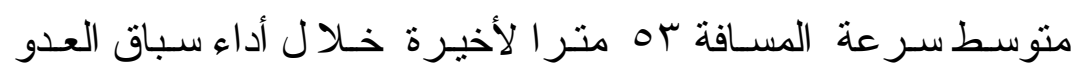

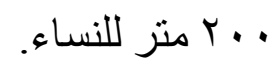

\section{تساؤلات البحث:}

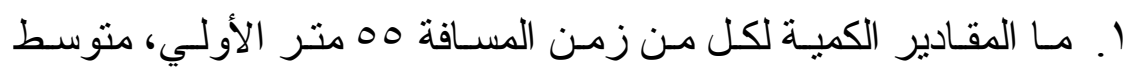

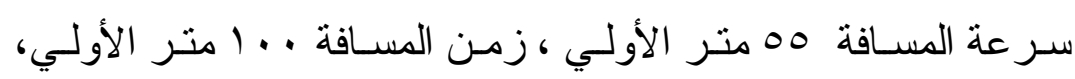

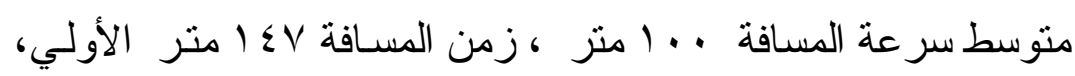

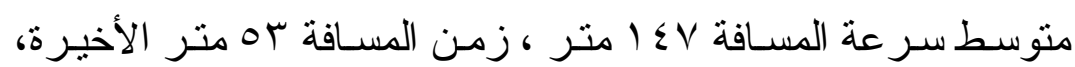

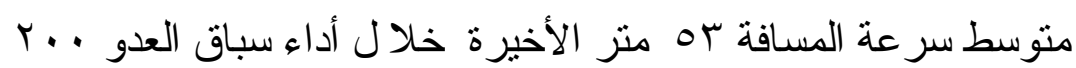
متر للنساء 
Y. مـا المنحنـي الخصائصسي الأنسـب لكـل مـن زمـن المسـافة 00 متر

الأولي، متوسط سر عة المسـافة ه0 متر الأولي، زمن المسـافة ..

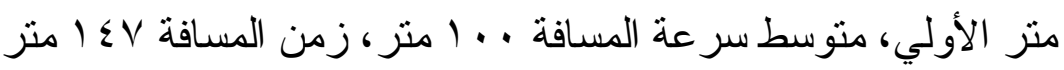

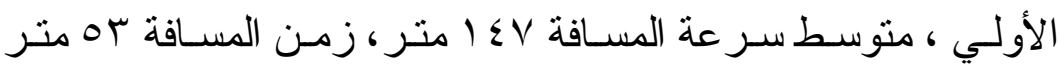

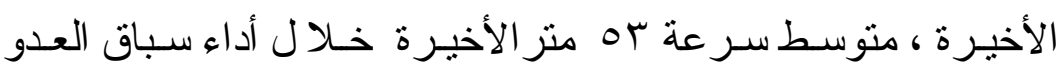

$$
\text { ؟. . }
$$

المصطلح و الرمز المستخدم في البحث

يعرض الجدول ( 1 ) المصطلح و الرمز المستخدم في البحث .

جدول (1)

المصطلح و الرمز المستخدم في البحث

\begin{tabular}{|c|c|c|}
\hline 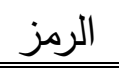 & المصطلح & s \\
\hline $\mathrm{X} 1$ & زمن المسافة من صفر إلي 00 منر الأولي ( ث ) & 1 \\
\hline $\mathrm{X} 2$ & السر عة المتوسط للمسافة من صفر إلي هـ منز الأولي(م / ث ) & r \\
\hline $\mathrm{X} 3$ & زمن المسافة .. متر الأولي ( ث ) & $r$ \\
\hline $\mathrm{X} 4$ & السرعة المتوسط للمسافة من 00متر إلي . . ا متر ( م / ث ) & $\varepsilon$ \\
\hline X5 & زمن مسافة V I ا متر الأولي ( ث ) & 0 \\
\hline X6 & السرعة المتوسط للمسافة من · . (متر إلي V\& ا متر ( م / ث ) & 7 \\
\hline $\mathrm{X} 7$ & زمن مسافة سه متر الأخيرة ( ث ) & 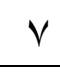 \\
\hline $\mathrm{X} 8$ & السرعة المتوسط للمسافة سه مترالأخيرة ( م / ث ) & $\Lambda$ \\
\hline X9 & الزمن المسجل قي نهائي مسابقة .. امتر عدو للنساء (ث) & 9 \\
\hline $\mathrm{X} 10$ & السرعة المتوسط لمسافة مسابقة . بامتر عدو للنساء ( م / ث) & 1 . \\
\hline
\end{tabular}




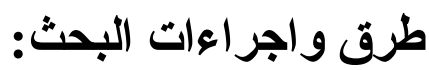

ا ـ منهج البحث: استخدم الباحث المنهج الوصفي لمناسبته لطبيعة هذه

الدر اسة .

r. عينة البحث : تم اختيار عينة البحث بالطريقة العمديـة وشملت كل

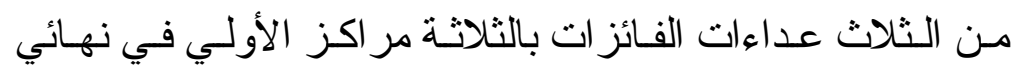

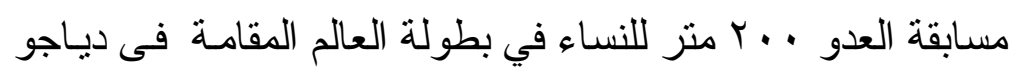

(Y Deagu

$$
\text { جدول (r) }
$$

خصائص عينة البحث

\begin{tabular}{|c|c|c|c|c|c|c|}
\hline الترتيب & 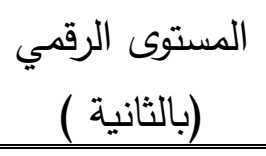 & 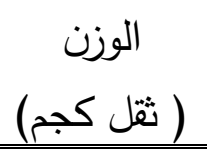 & $\begin{array}{l}\text { الطول } \\
\text { (متر) } \\
\end{array}$ & $\begin{array}{c}\text { السن } \\
\end{array}$ & الجنسية & 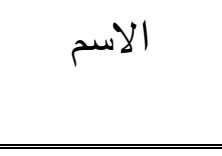 \\
\hline 1 & YT.YY & 71 & r.7. & r. & JAM & $\begin{array}{c}\text { Veronica } \\
\text { C. }\end{array}$ \\
\hline r & TY.TV & or & $1.7 \pi$ & سז & USA & $\begin{array}{c}\text { Carmelita } \\
\text { J. }\end{array}$ \\
\hline r & r..$\leqslant r$ & 00 & 1.71 & rv & USA & Allyson F. \\
\hline & rt.TE & אז. & 1.70 & r. & \multicolumn{2}{|c|}{ المتوسط الحسابى } \\
\hline & $\cdot .1 \cdot \varepsilon$ & $\varepsilon .17$ & $\because \cdot r$ & r... & \multicolumn{2}{|c|}{ الانحر اف المعيارى } \\
\hline & TY.YT & 71 & 1.71 & r... & \multicolumn{2}{|c|}{ الحد الأعلى } \\
\hline & $r$ r. $\leqslant Y$ & r & 1. & $r v . .$. & \multicolumn{2}{|c|}{ الحد الأدنى } \\
\hline & $r . . \cdot-$ & $\Lambda$ & $\because .0$ & 7 & \multicolumn{2}{|r|}{ المدي } \\
\hline & I,rqr- & 1,94 & $1, V r$ & $\cdot, \cdots$ & \multicolumn{2}{|c|}{ معامل الالتو اء } \\
\hline
\end{tabular}


ويتضح من جدول (Y) أن معامل الالتو اء لكل من خصائص عينة البحث قيد

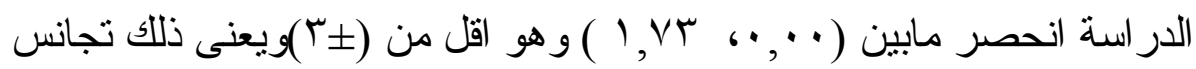
افر اد عينة البحث فى كل من متغيرات السن ، و الطول ، و الوزن ،و المستوى

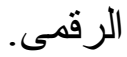

\section{وسائل جمع البيانات:}

1. الـرقم الرســي : حصـل الباحـث علي الـرقم الرســي وطـول ووزن الجسم و السن لكل عداءة من التقرير النهائي لمسابقات . . rمنز عدو

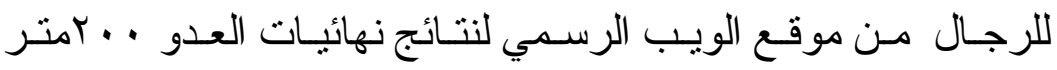
لبطولة العالم لألعاب القوي المقامة بدياجو Deagu 11 (1 • م م . ( ( )

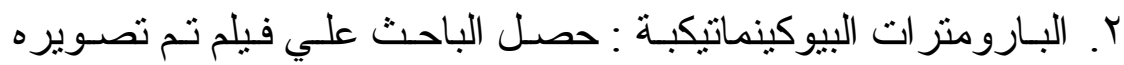
لمسابقات نهائي . . ب منز عدو للنساء بكامير ا ت فيديو (تردد كل منها

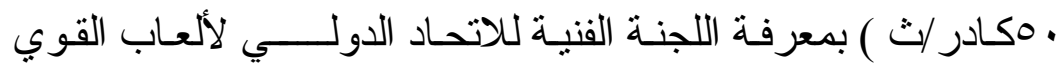

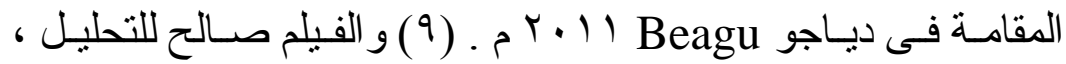
ولتسهيل عملية التحليل قام الباحث بتقسيم الأداء لمر احل كما في شكل (1) ، كما قام الباحث بتحليل في المتوسط ، . 1 كادر في كل محاولة

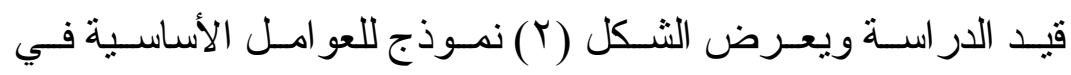

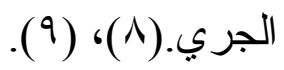




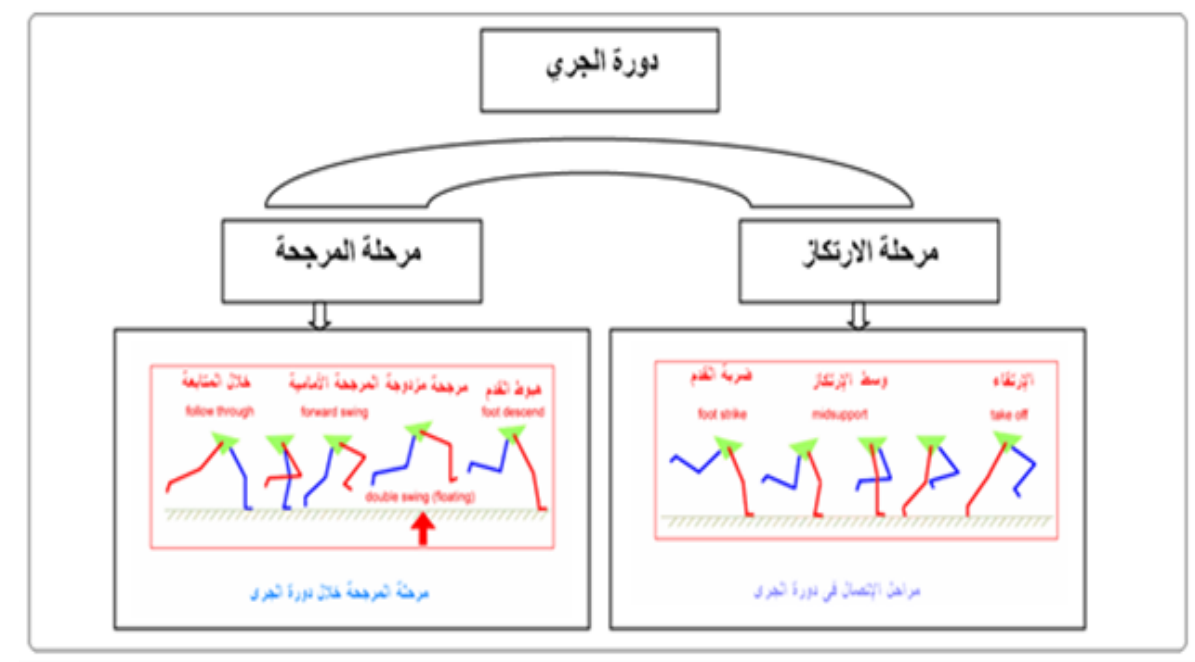

شكل(1)

مر احل أداء دورة الجرى

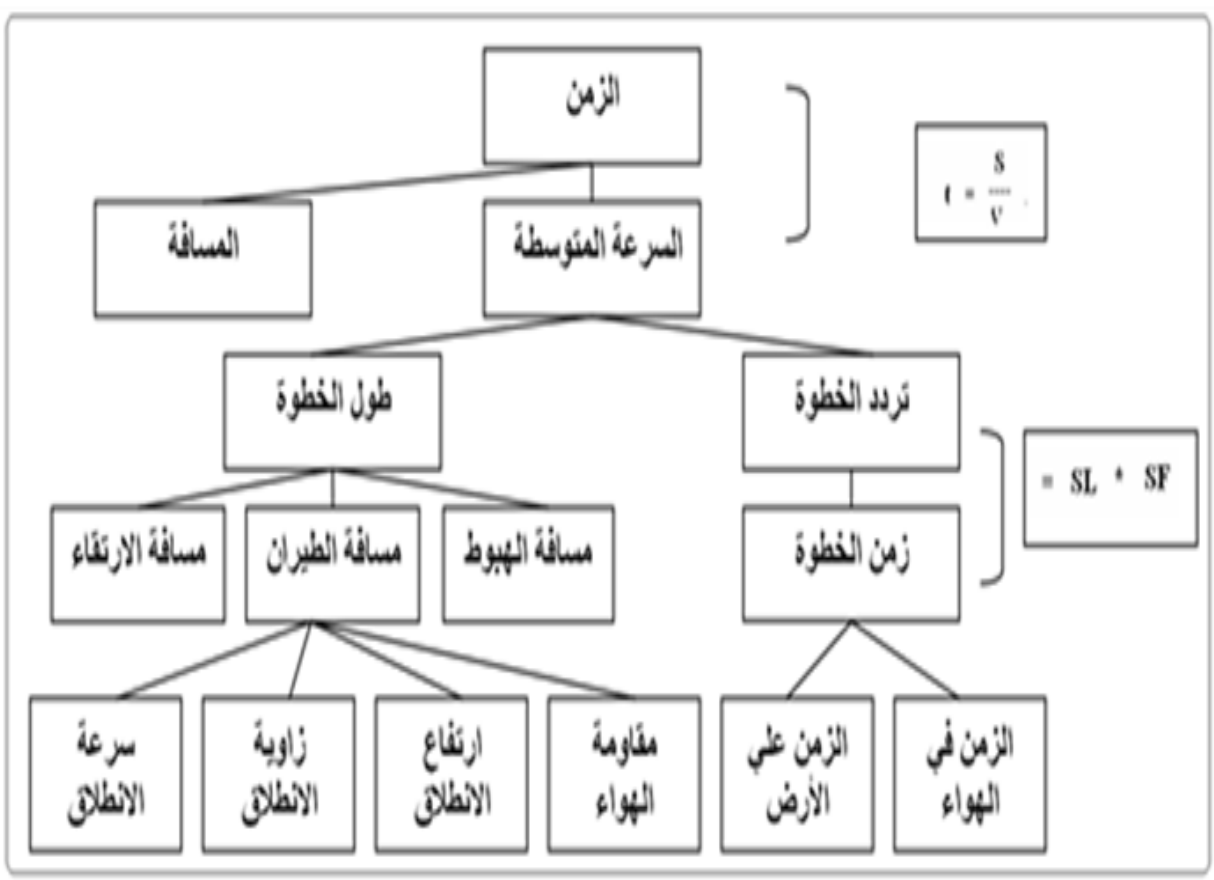

شكل (r)

العو امل الأسساسية في الجرى 


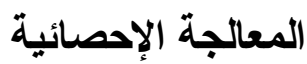

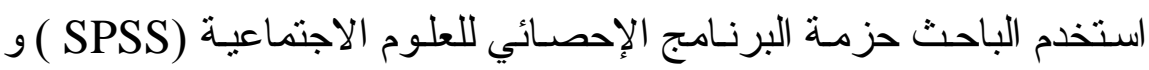

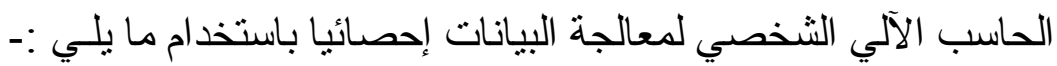

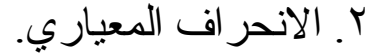

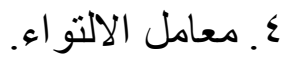

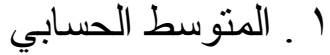

ب ال ـ الحدين الأدني و الأعلي

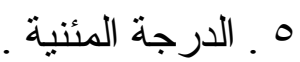

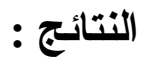

يعرض الجدو لان ( r ، ع ) المتوسط الحسابي و الانحر اف المعياري و

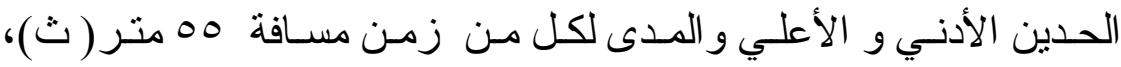

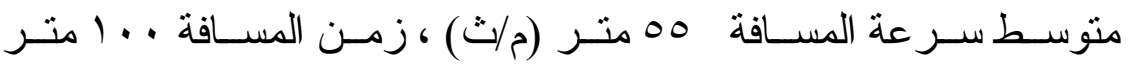

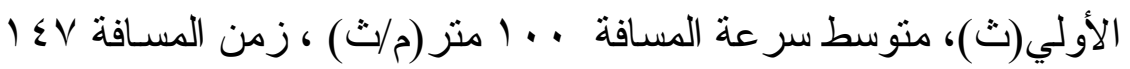

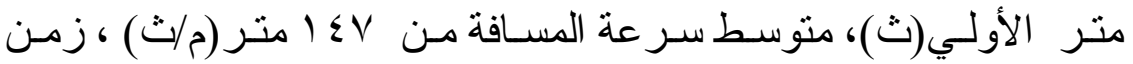

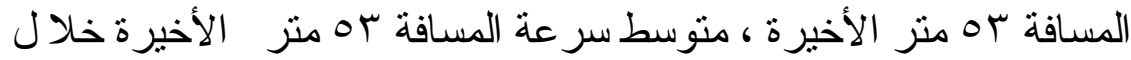

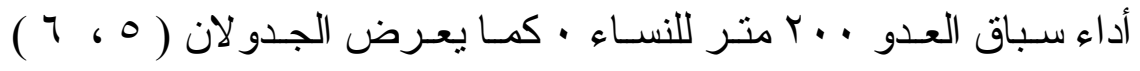

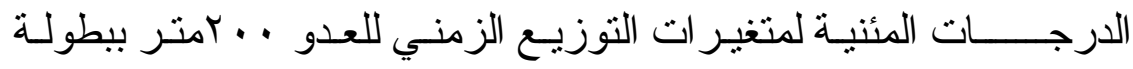

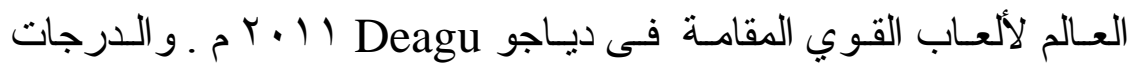

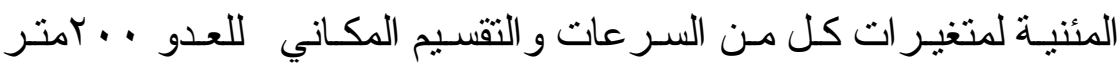

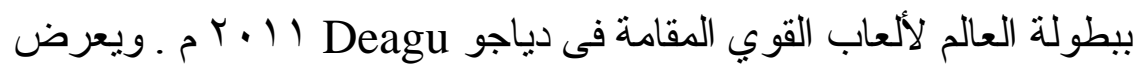

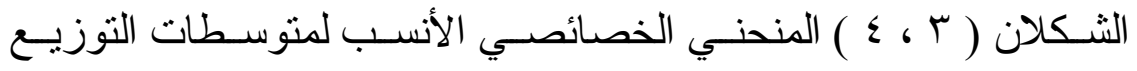

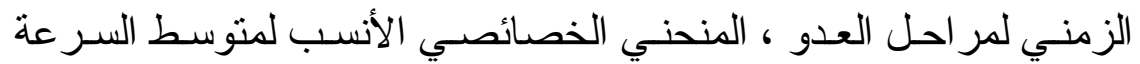

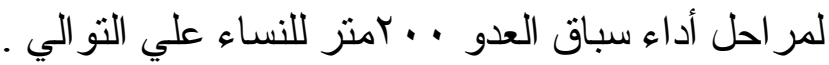




\section{جدول (r)}

المتوسط الحسابي والاتحر اف المعياري و الحدين الادني و الاعلي والمدي

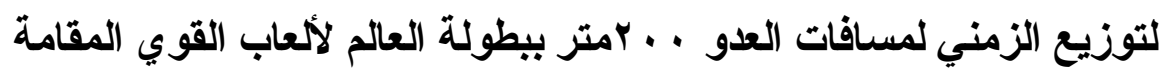

في دياجو

\begin{tabular}{|c|c|c|c|c|c|c|c|c|}
\hline معامل الالتو اء & المدي & 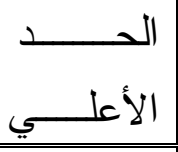 & 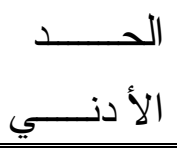 & \begin{tabular}{|l} 
الانحر اف \\
\end{tabular} & المتوسط & وحدة & البيان & 5 \\
\hline 1.81 & $.1 \leq$ & $7.7 \leq$ & 7.0 & .111 & 7.01 & ث & 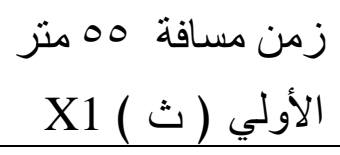 & 1 \\
\hline $.111-$ & r. & 11.0 & $1 \cdot r$ & סדון & 11.18 & $\dot{H}$ & 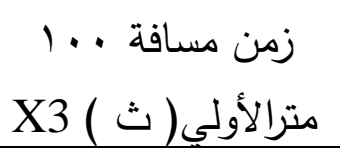 & r \\
\hline $1.7 .0_{-}$ & דr. & $\mid 1.71$ & IV.YO & .190 & iv.vo & 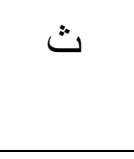 & 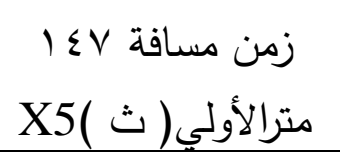 & r \\
\hline 1.91 & $.1 \leq$ & $\varepsilon . V \varepsilon$ & $\varepsilon .7$. & $\cdot r \cdot \Lambda$ & $\varepsilon .7 \pi$ & ث & 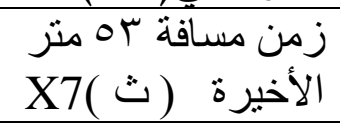 & $\varepsilon$ \\
\hline 1.rqr_ & $\cdot .9$ & Tr. & T.T & $.1 \cdot \varepsilon$ & rT.rE & $\dot{H}$ & 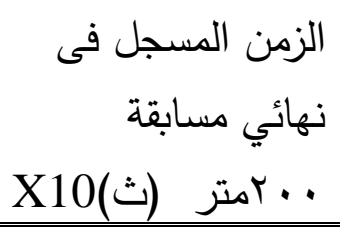 & 0 \\
\hline
\end{tabular}

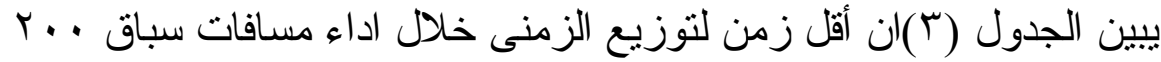

منر عدو ببطولة العالم لألعاب القوى المقامة فى دياجو Deagu 11 • ـ آم .كان زمن مسافة 00منز الأولى حيث كان منتسطه ( 7,01 ثt

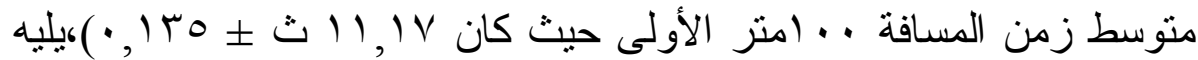

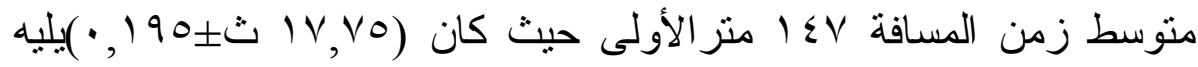

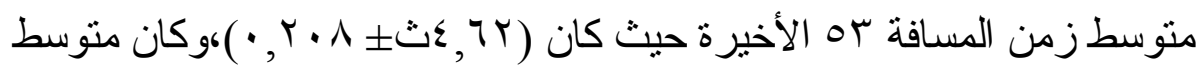

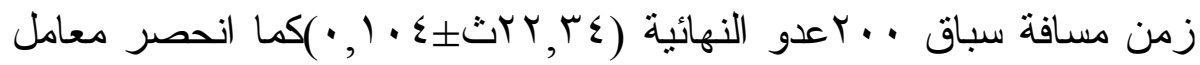




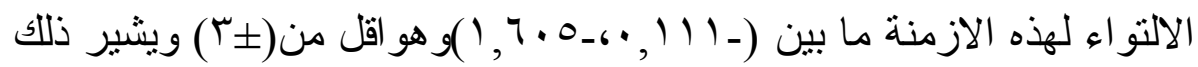

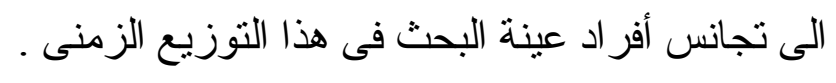

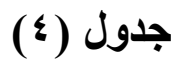

المتوسط الحسابي والاحراف المعياري و الحدين الادني و الاعلي

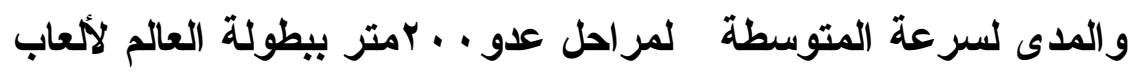
القوي المقامة فى دياجو Deagu

\begin{tabular}{|c|c|c|c|c|c|c|}
\hline الهـــــدي & 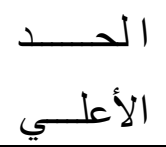 & 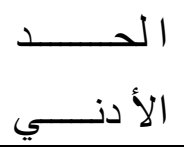 & الانحر اف & الحسابي & و القياس & البيان \\
\hline .19 & 9.0 & $\Lambda . \wedge T$ & $\because 90$ & 1.90 & م /ث & منوسط سرعة مسافة \\
\hline$\cdot \varepsilon$. & 11.00 & 11.10 & $\cdot r \ldots$ & $11 . \pi 4$ & م /ث & متوسط سر عة مسافة \\
\hline$\cdot, r)$ & $1 \cdot, 91$ & $1 \cdot, V V$ & $\cdot, 11 \varepsilon$ & 1,01 & م/ث & متوسط سر عة مسافة \\
\hline. .19 & $1 . \Gamma$. & $1 . .11$ & $\because 90$ & $1 \cdot Y_{1}$ & م /ث & متوسط سر عة مسافة \\
\hline r & 1,90 & $\Lambda,{ }^{\prime} Y$ &, .90 & 1,90r & م /ث & متوسط سر عة مسافة . . كمتر (X9) \\
\hline
\end{tabular}

يوضح الجدول (乏)أن أكبر منوسط لسرعة المتوسطة خلال اداء مسافة

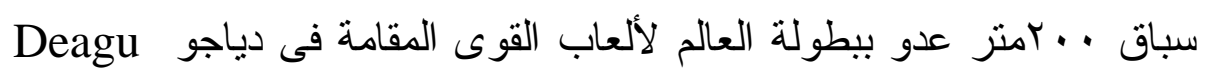

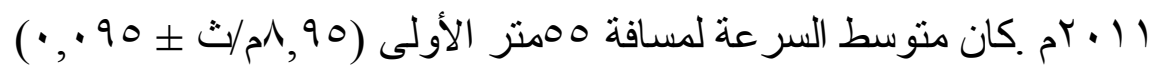

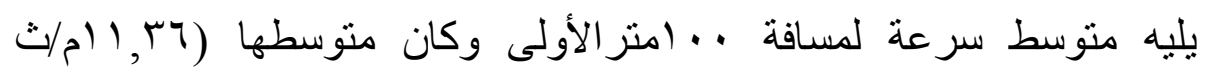

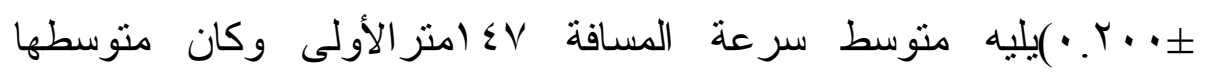




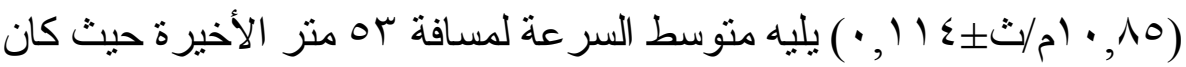
متوسطها ( اب, • ام/ثده 90 •, • )كما انحصر معامل الالتو اء لمتوسط السرعات

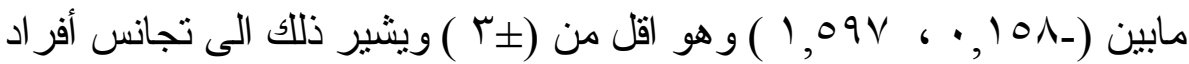
عينة البحث فى متوسط هذه السر عات .وكان متوسط السر عة المتوسطة لمسافة

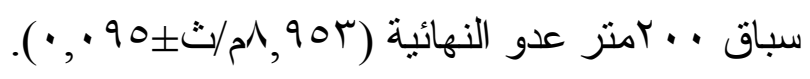

$$
\text { (0) جدول (0) }
$$

الارجات المئنية لتوزيع الزمني لمسافات العدو . . rمتر ببطولة العالم

\begin{tabular}{|c|c|c|c|c|c|c|}
\hline 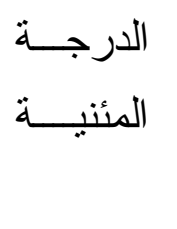 & زمن مسافة & زمن مسافة & زمن مسافة & $\begin{array}{l}\text { زمن مسافة } \\
\text { _. . ام (ث) }\end{array}$ & زمن المسافة & المئنـــــة \\
\hline $1 \ldots$ & YI.VY & $\varepsilon . Y V$ & $1 \mathrm{~V} .1 \mathrm{~V}$ & $1 . . V V$ & T T.Y & $1 \ldots$ \\
\hline 9. & 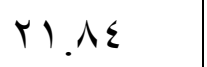 & $\varepsilon . \Gamma \varepsilon$ & $I V . r A$ & $1 . .10$ & r. & 9. \\
\hline$\Lambda$. & Y). $9 \mathrm{~V}$ & $\varepsilon . \leqslant 1$ & IV.z. & $1 \cdot .94$ & $7 . r v$ & $\Lambda$. \\
\hline v. & $r r_{.} \cdot q$ & $\varepsilon . \leqslant 0$ & IV.Or & 11.1 & $7 . \leqslant \varepsilon$ & $v$. \\
\hline 7. & Yr.YY & $\varepsilon .00$ & 1V.7 & 11.99 & 7.901 & 7. \\
\hline 0. & & $\varepsilon .7 r$ & IV.Vo & $11.1 \mathrm{~V}$ & 7.01 & 0. \\
\hline$\varepsilon$. & $r r_{.} \Sigma V$ & 5.79 & $I V . \wedge v$ & $11 .{ }^{1}$ & 7.70 & $\varepsilon$. \\
\hline$r$. & $r r . \wedge q$ & $\varepsilon . \vee 7$ & $1 \vee .91$ & אז.11 & $7 . V Y$ & r. \\
\hline$r$. & Yr.VI & $\Sigma . \wedge \mu$ & 11.1. & $11 . \leqslant 1$ & 7.19 & $r$. \\
\hline 1. & $r Y . \wedge \varepsilon$ & $\varepsilon .9$. & $M \Lambda . r Y$ & $11 . \leqslant 9$ & $7 . \wedge 7$ & 1. \\
\hline صفر & YY.qT & $\leqslant .9 V$ & I^.؟ & 11.01 & 7.94 & صفر \\
\hline
\end{tabular}
لألعاب القوي المقامة فى دياجو Deagu 
يعرض جدول (0):الدرجات المئينية لتوزيع الزمنى لمسافات العدو ... بمتز

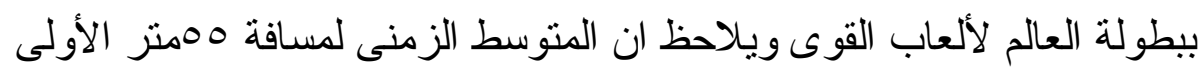

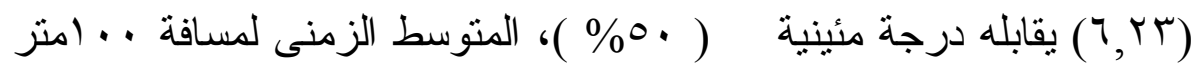

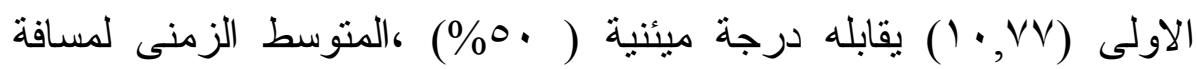

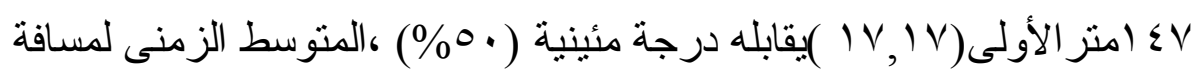

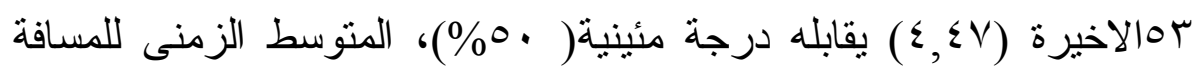

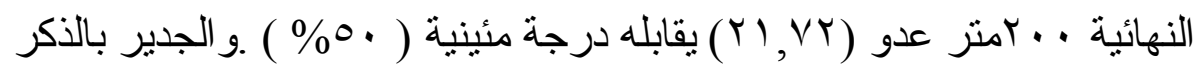

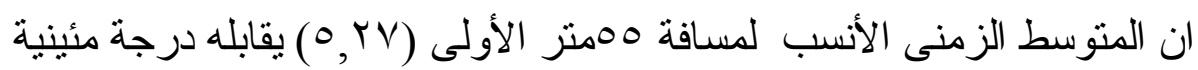

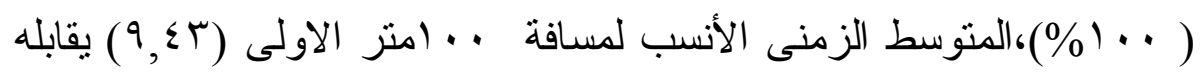

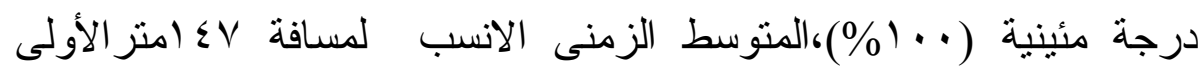

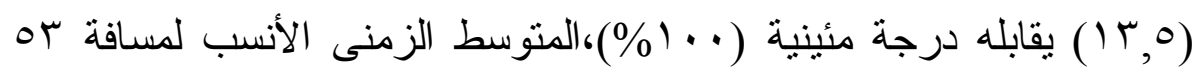

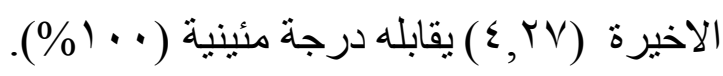


جدول (7)

الارجات المئنية لسرعة المتوسطة لمراحل أداء عدو . . ب امتر بيطولة العالم

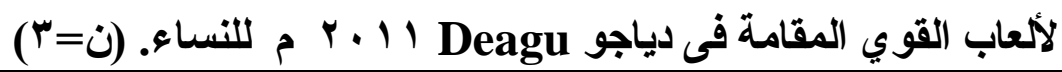

\begin{tabular}{|c|c|c|c|c|c|}
\hline الدرجـــــة المئنـــــــة & المتوسطة & ل المتوسطة & ل المتوسطة المسافة & المترسة المسة & المانجنســـة \\
\hline $1 \ldots$ & $1 . .79$ & $11 . \leqslant r$ & צr.Yו & $9 . \leqslant r$ & $1 \ldots$ \\
\hline 9. & $1 . .09$ & 11.51 & $1 Y .17$ & Q. & 9. \\
\hline$\Lambda$. & 1.0. & 11.19 & 11.97 & $9.4 \varepsilon$ & $\Lambda$. \\
\hline$v$. & $1 \cdot . \varepsilon \cdot$ & $11 . .1$ & 11.87 & $9.1 \leq$ & $v$. \\
\hline 7. & $1 . r 1$ & 1.97 & 11.07 & 9.0 & 7. \\
\hline 0. & $\mid \cdot r)$ & $1 . .10$ & $11 . r 4$ & 1.90 & 0. \\
\hline$\varepsilon$. & $1 . .1 r$ & $1 \cdot . v \leq$ & 11.17 & $\wedge . \wedge 7$ & $\varepsilon$. \\
\hline$r$. & $1 \cdot . \cdot r$ & $1 . .7 r$ & 1.97 & $\Lambda . \vee T$ & r. \\
\hline$r$. & $9 . \wedge \mu$ & $1 . .01$ & $1 . .87$ & A.TV & $r$. \\
\hline 1. & $9 . V \varepsilon$ & $1 . r q$ & $1 . .07$ & $\Lambda .0 \mathrm{~V}$ & 1. \\
\hline صفر & $9.7 \varepsilon$ & $1 . . \mathrm{r}$ & $1 . .4$ & $\Lambda . \leqslant \Lambda$ & صفر \\
\hline
\end{tabular}

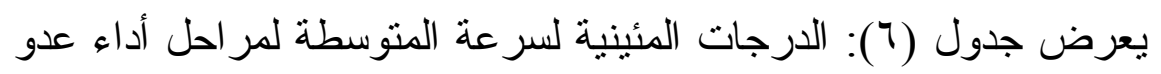

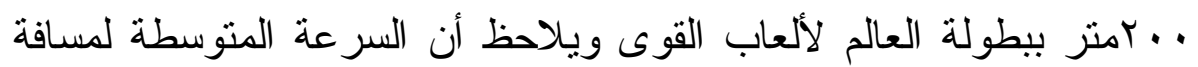

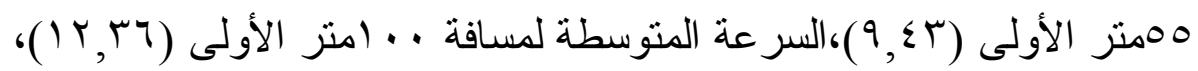

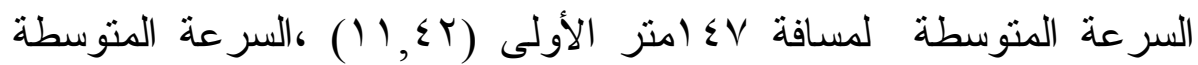

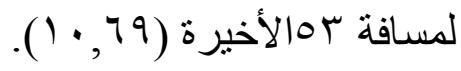




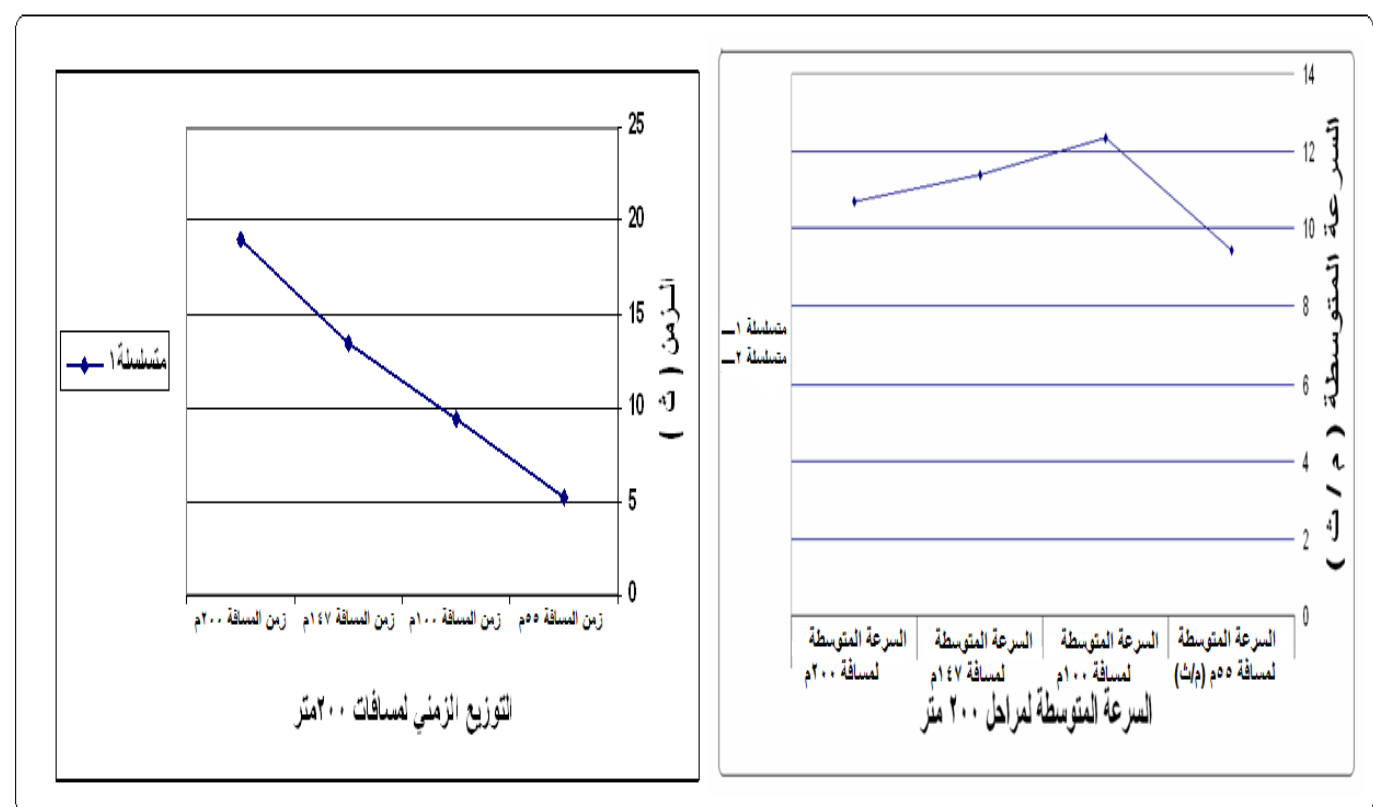

شكل (َ): المنحني الخصائصي الأسب لمتوسطات

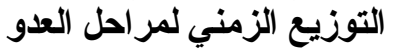

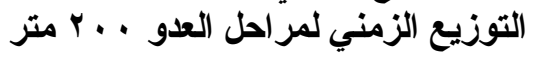

شكل (ع): المنحني الخصائصي الأسبب

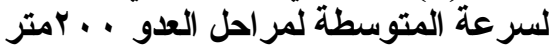

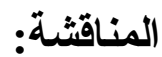

أظهرت نتـائج تحليـل التوزيـع الزمنـي للمســار الحركي لمر احـل العـدو

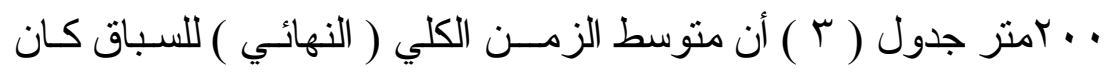

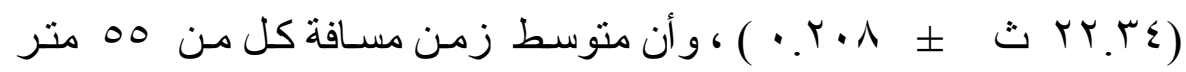
الأولي كان (1.01 7 ث

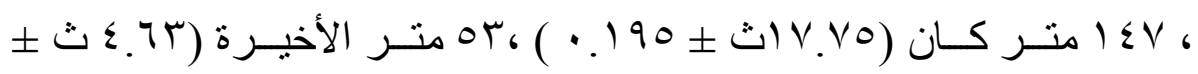

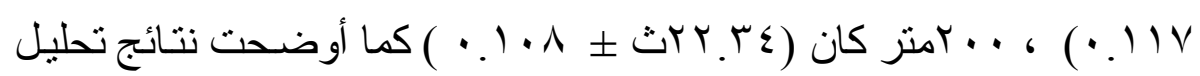


السر عة المتوسط لكل مسـافة لمر احل .امتر عدو كانت لمسـافة 00 متر

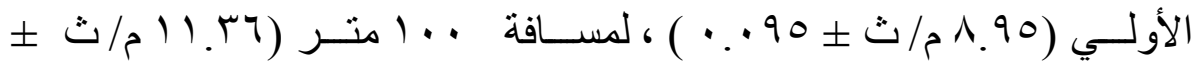

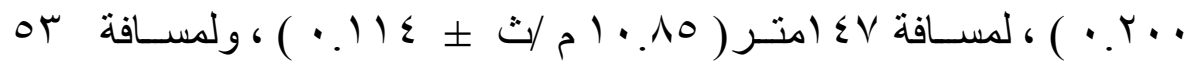

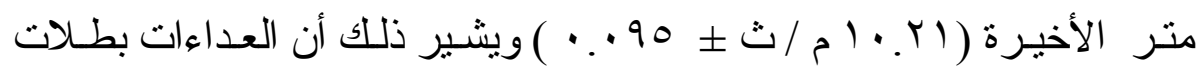

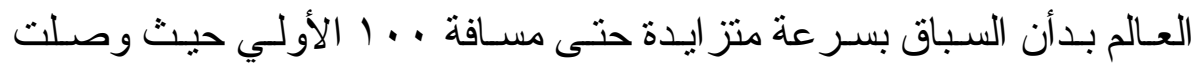
السـر عة المتوسطة إلي قمتهـا ثم حدث انقلاب للسـر عة المتوسطة مـن مسـافة

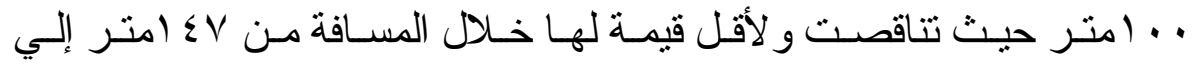

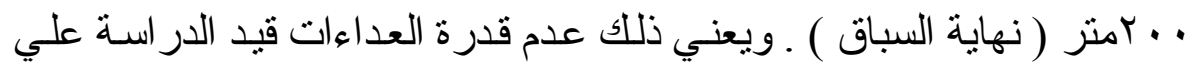
الاستـمر ار في تز ايد السـرعة و الحفاظ علي السرعة المكتسبة و عدم تتاقصـها حتى نهايـة السـباق الأمـر الذي أدي إلـي زيـادة الـزمن الكلـي للسباق ـ ويفسـر الباحث هذا القصور في الأداء في ضوء عـاملين: الأول ويرجـ للأعداد البدني

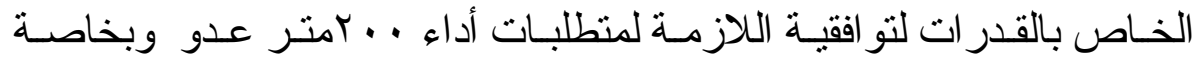
تحمـل السـرعة ، وتحمـل القوة والقوة المتفجـرة ــ و العامـل الثـاني يرجـع إلـي التوزيع الأمنل لسرعة العدو في سباق .امتر حيث يجري العداءات المائة

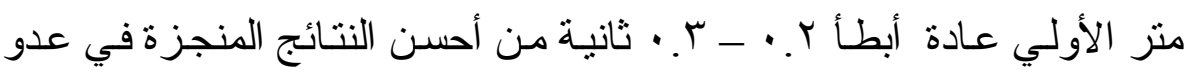

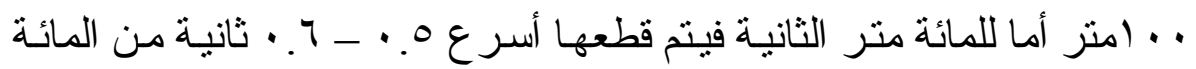
متر الأولي ـ وبناء ا علي ماسبق تتحقق الإجابة عن التساؤل الأول للبحث .

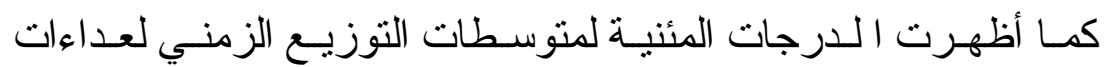

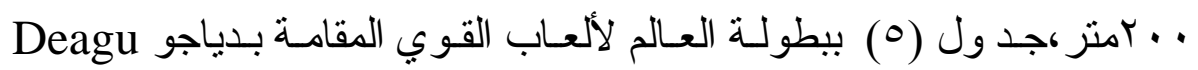

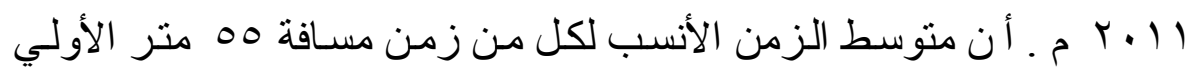

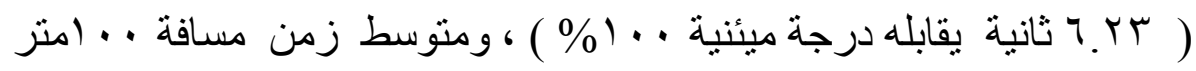

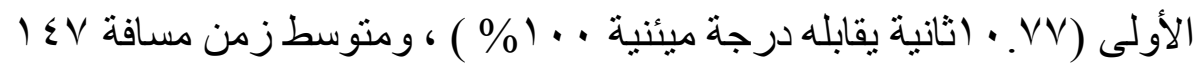

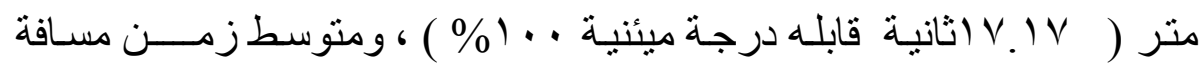

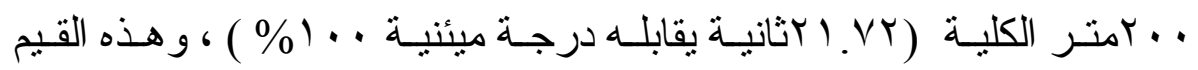


لمتوسطات أزمنة المسافات قيد الدر اسـة خـلال العدو . . كتير للرجال تعتبر

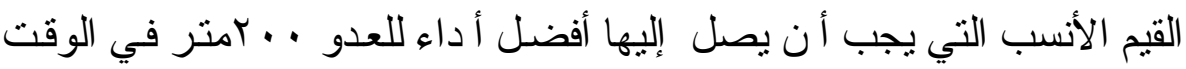

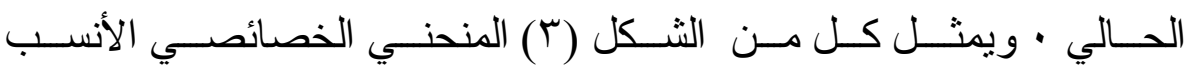

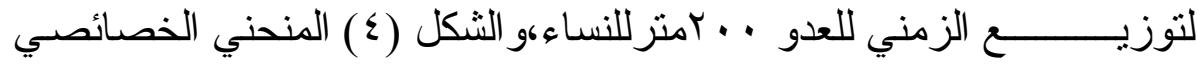

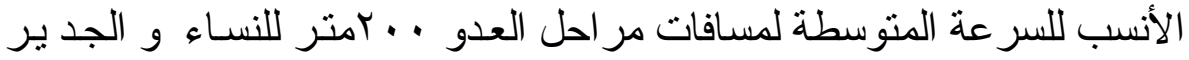

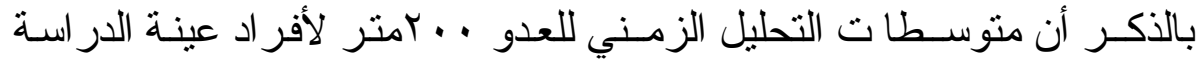

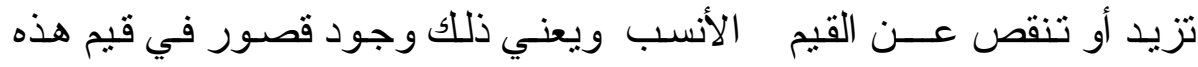

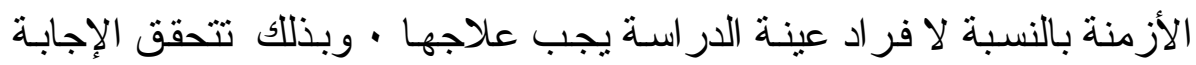

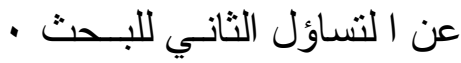

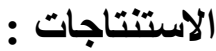

في حد ود عينـة البحث ودقة وسـائل جمع البيانـات و النتائج ومناقشتها

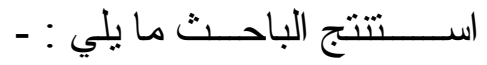

هُ انحصرت قيم منوسطات التوزيع الزمني للمسار الحركي لمر احل اداء

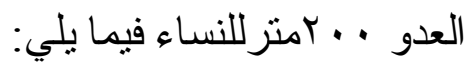

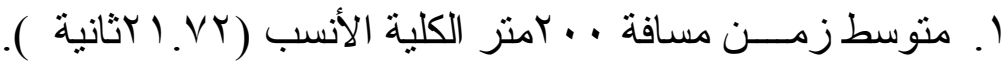

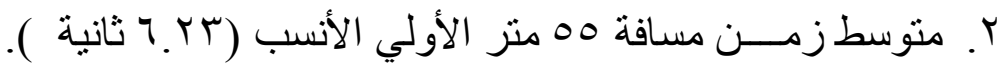

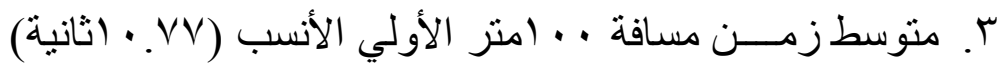

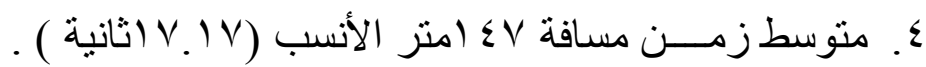

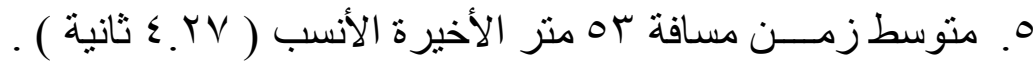
انحصرت قيم منوسطات منوسط السر عة المنوسطة لمر احل أداء العدو

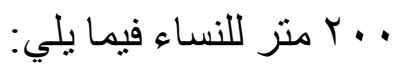

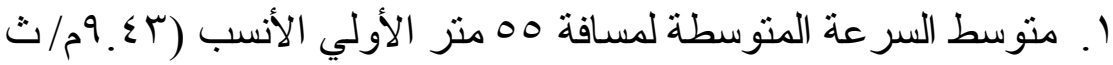

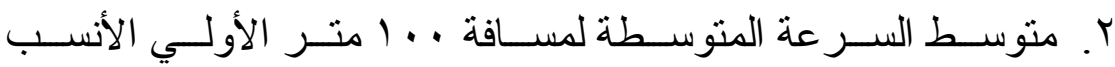

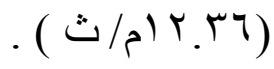




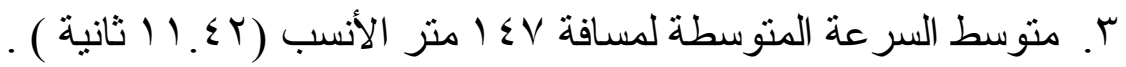

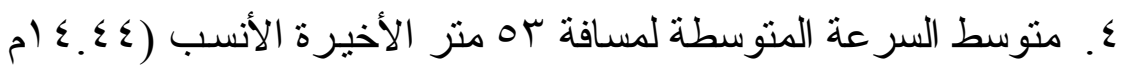

$$
\text { . (ث) }
$$

حدد الباحث المنحني الخصائصي الأنسب لكل من النتوزيــــــــع الزمني للعدو · بمتر للنسـاء، المنحني الخصائصي الأنسب للسر عة المتوسطة

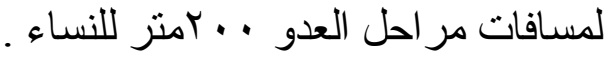

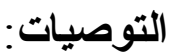

في حدود النتائج ومناقشتهاو الاستتناجات أوصي الباحث بما يلي: -

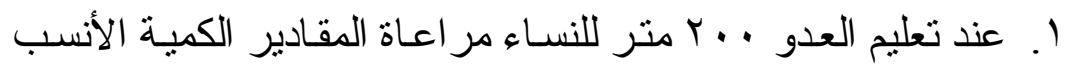
لكل من متغير ات الزمن، و السر عة المتوسطة خـلال مسـافات المسـار الحركي التي توصلت لها هذه الدر اسة.

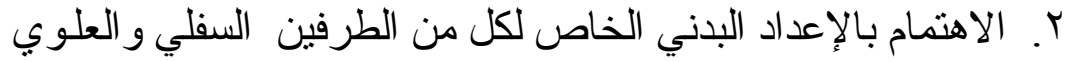

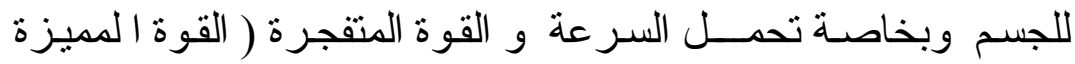

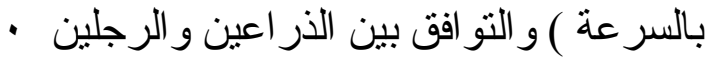

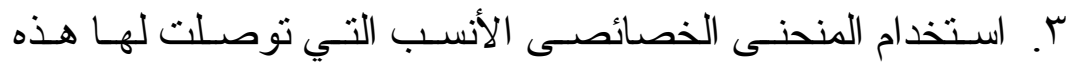

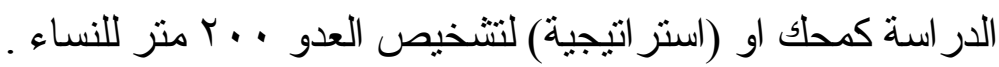

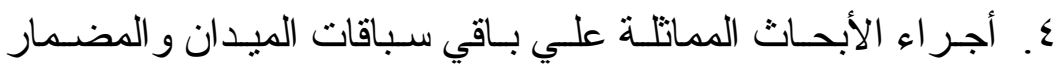

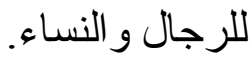

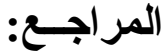

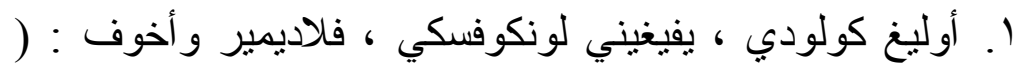

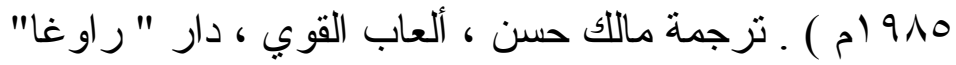

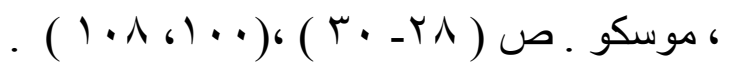

r r. بسطويسى احمد:(997(1)سباقات المضمارومسابقات الميدان

تعليم - تكنيك - تدريب،دار الفكر العربى،القاهرة.ص(VV) 
r. زكى محمود درويش، عادل محمودعبد الحافظ (997): المعارف، القاهرة:ص(Y) (YV_YT)

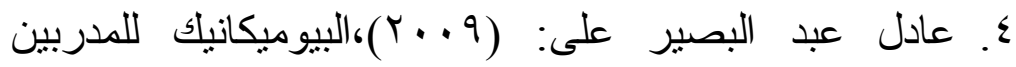

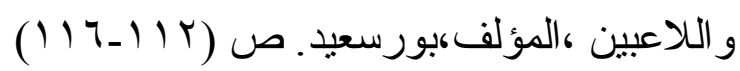

5. Hay James G.: (1978), the Biomechanics of Sports Techniques, Second Edition, Prentice - Hall, Inc., Englewood Cliffs, and USA. P (382, 3994 -398 )

6. Hay James G.: (1993), Track and field Running (Chapter 15). In : Biomechanics of sports techniques $\left(4^{\text {th }}\right.$ ed. ) .Pp ( $396-423$ )

7. Fred Housed , : ( 1964 )," Mechanical Analysis of the Running Movement" , in Run,Run,Run, ed. By Fred Wilt (Los Altos, Calif,: Track \& Field News). Pp. ( 41, 240 )

8. Karol Hoffman , : 1965 ), "The Relationship between the Length and Frequency of stride, stature and Leg Length" Sport [Belgium ] , VIII, No.3, ( French)

9. Karol Hoffman , : ( 1967 ), "The Length and Frequency of stride Sprinter" Treatises, Texts and Documents WSWF in Poznan Series, Treaties No.17. ( Polish )

10. http://www.iaf.org/statistics/toplists/index.html IAAF World Championship Daegu 2011. 
(المستخلص

المنحني الخصائصي الأسب لكينماتيكية مر احل اداء سباق ، . . متر عدو

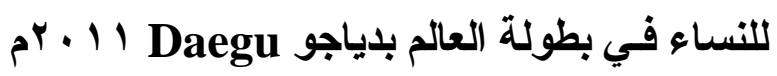

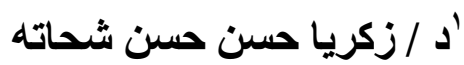

هدفت هذه الدر اسة إلي التعرف علي : (1) المقادير الكميـة لكل من

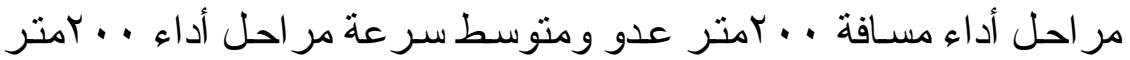

عدو للنسـاء · ( r ) المنحنـي الخصائصسي الأمثنل لكل مـن مر احل اداء . . . . . . الثلاثة عداءات الحاصـلات علي المركز الثلاتثة الأولي في نهائي مسـابقة

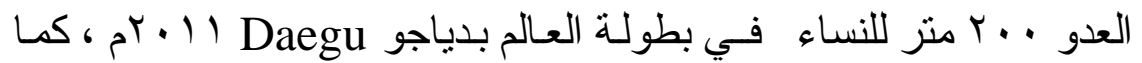
حصل الباحث علي الرقم الرسمي وطول ووزن الجسم والسن لكل عداءة مـن التقريـر النهائي لمسـابقات . . بمتـر عدو للنسـاء مـن موقـع الويـب الرسمي لنتائج نهائيات العدو .امثر لبطولة العالم لألعاب القوي المقامـة

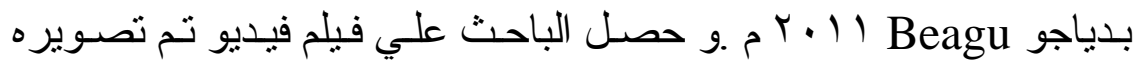
لنهائي مسـابقة . . بمتر عدو للنسـاء فـي بطولة العـالم بدياجو مaegu

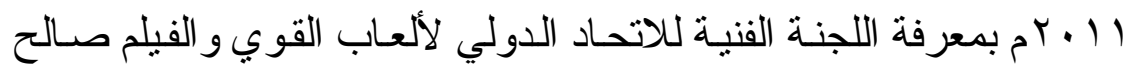
للتحليل كمـا تم تحليل فيلم الفيديو باستخدام برنـامج التحليل الفوري وين

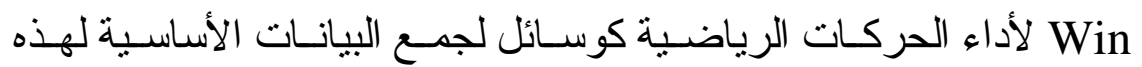
الدر اسة ، كما استخدم الباحث حزمة البرنامج الإحصائي للعلوم الاجتماعية و الحاسـب الآلكي الشخصـي لمعالجـة البيانـات إحصـائيا ـوقـد (SPSS) أسفرت أهم النتائج عن تحديد المقادير الكميـة لكل مـن التوزيـع الزمني و السر عة المتوسطة خلال مر احل أداء العدو .. متر للنساء ، و تحديد كل

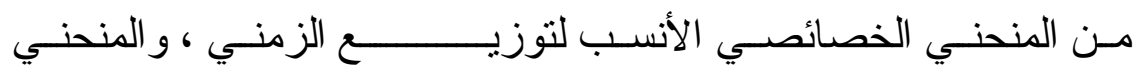




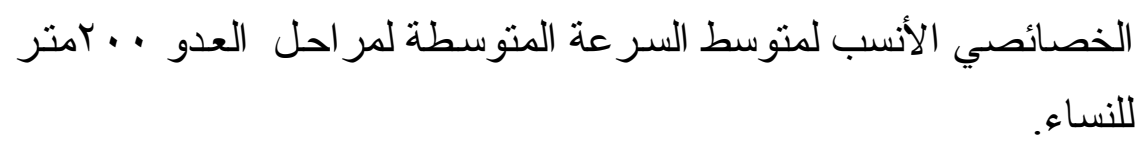

'د / ذكريـا حسـن حسن شـحاته: مـرس بقسـم علـوم الحركـة الرياضـية، كليـة التربية الرياضية بدمياط، جامعة دمياط.

Abstract

The curve characteristically appropriate kinematical women's 200 meters at The World Championships Daegu 2011

${ }^{1}$ Dr / Zakarya Hassan H. Shehata

This study aimed to identify: (1) the quantity of all ingredients of a time distance and total time of the 200 meters and the average speed for the 200 meters during the performance of the women's $200 \mathrm{~m}$.

(2)the curve characteristically best suited to each time the distance $55 \mathrm{~m}$, average speed distance 55 meters, 100-meter distance, average speed, distance $100 \mathrm{~m}$, long distance 147 meters, an average speed of 147 meters distance, speed time distance 53 meters, the average speed is 53 meters during the last performance of the women's 200 meters. The sample was selected by intentional three included sprinters on the first three place in final women's 200 meters at the World Championships Daegu 2011, a researcher on the official digital length, body weight and age for 
each sprinters from the final report of the competitions in the women's 200 meters from the official website of the results of the finals of the 200 meters World Athletics Championships held in Beagu 2011. The researcher also received a video filmed for the final women's 200 meters at the World Championships Daegu 2011 and the film fit for analysis and analysis of video movie using instant analysis and Win for sports movements as basic data collection for this study، The researcher also used statistical program package for social science (SPSS) and the PC to process the data statistically. The main results have resulted in the identification of ingredients quantity per time distribution and average speed during the performance of the women's $200 \mathrm{~m}$ Identification of the most appropriate distribution of characteristically curve, and the curve for the average characteristically average speed for the 200 meters sprint stages.

${ }^{1}$ Dr / Zakarya Hassan H. Shehata : Lecturer of sports

Sciences Department, Faculty of physical education in Damietta, University of Damietta. 